\title{
INDIAN TRADITIONAL MEDICINE IN WESTERNS EYES
}

\author{
Kamath Madhusudhana \\ Associate Professor, Division of Ayurveda, Centre for Integrative Medicine and Research (CIMR), \\ Manipal Academy of Higher Education, Manipal, Karnataka, India -576 104
}

Article DOI: https://doi.org/10.36713/epra4336

\begin{abstract}
Ayurveda is a traditional healing method in India for more than 5000 years, preserved from ancient pieces of literature, namely Atharva Veda. Ayurveda is believed and practiced commonly in India to promote robust human life and eliminate diseases as a person can maintain balanced constitutions which are called Tri-Dosha. The method is especially present in the practice of traditional medicines and is used to prescribe certain forms of treatment upon particular diseases. As such, herbal and related drugs are those of the most important parts mentioned in the traditional Ayurvedic texts. Despite their curing potential claimed in the texts, many cases now have been reported poisoned due to the use of these drugs. In the scope of our paper, the study would unveil the picture of the practice of Ayurvedic medicines nowadays and entail some answers for the reasons of drug poisoning.
\end{abstract}

\section{INTRODUCTION}

Ayurvedic drugs for internal usage exist in varied forms: pills, decoctions, wines, teas, syrups 1 . Usage of Ayurvedic drugs can include home-remedy supplements such as milk, water, and honey. In this report, the two most concerning ingredients of drugs are herbal formula and metal-based therapeutics. The herbal formula includes medicinal herbs and decoctions with herbs. Herbs are thought to be "natural" and safer compared to biomedicine. They are also easy to be found and bought freely in markets and the internet under lax regulations ${ }^{2}$.

Heavy metal, in its term, is defined as metals with high densities, usually found in industrial processes. Heavy metals have been used as both raw and organic materials in Ayurvedic practices of medicine since ancient times ${ }^{3}$. They were thought to bring harmony and balance between the human and the universe. Heavy metals were viewed as a vital role in supporting the immune system; without them, the condition of human health could be harmed by diseases. Throughout some sorts of the boiling process, the toxicity in heavy metals could be reduced. However, the use of heavy metals in Ayurvedic drugs did not obtain desired therapeutic effects but sometimes caused more severe harm to patients.
Metal-based therapeutics is called to the attention of the public about its adverse effects and its inability to detoxify completely of heavy metals. Arising concerns over the heavy materials take part in the main topic of the safety of Ayurvedic drugs. The three most common metals are found in Ayurvedic products: Lead, Mercury, and Arsenic. While Ayurvedic drugs are widely used in India, there is no global consensus on the limit level of heavy metals, up to which these metals cause harm the health. Rather, the limiting boundaries to the consumption of each metal are more country-specific according to their population health. This report also relates to WHO's recommendations of the levels of these heavy metals in drinking water and draws some correlations of heavy metal usages around the world.

\section{Heavy metals}

Mercury's medicinal use raises the central attention of safety concerns in Ayurvedic drugs. From Ayurvedic conceptions, mercury elements in the drug could strengthen potency and eyesight, and further, obliterate all diseases ${ }^{4}$. The medicinal effects and uses could be traced back to the oldest works of literature, the Carakasaṃhitā and the Suśrutasaṃhitā ${ }^{4}$. The purification processing of mercury is also mentioned; one primary method includes grinding 


\section{SJIF Impact Factor: 6.260| ISI I.F.Value:1.241| Journal DOI: 10.36713/epra2016 ISSN: 2455-7838(Online) \\ EPRA International Journal of Research and Development (IJRD) \\ Volume: 5 | Issue: 4 | April 2020 \\ - Peer Reviewed Journal}

mercury with decoctions of leadwort and aloe juice for several days. Mercury was viewed as a core to unite with other metals and could be 'sealed' by sulfur to reduce its toxicity.

Mercury mostly found in Ayurvedic drugs in the form of Mercury sulfate. WHO're experts recommend not ingesting and avoiding any physical contact with the mercury compounds which cause irritation and severe burns. Daily intake of raw mercury is recommended below 0.05 ug from drinking water, and any of its vapour is avoided. The threshold level of mercury in drinking water should be about $0.01 \mathrm{mg} / \mathrm{L}$. People exposed to mercury at a concentration of $0.02 \mathrm{ug} / \mathrm{L}$ for several years could show some abnormal signs of nervous systems ${ }^{5}$.

Another most harmful heavy metal residual in some Ayurvedic drugs is lead. Practices of medicine involving lead have faced strong criticism from several international organizations including the WHO and the World Bank. Lead detrimentally affects the mental health of children; children exposed to $11 \mathrm{ug} / \mathrm{dl}$ of lead could drop 11.1 points below the average IQ. Although lead, in Ayurveda, is applied in treatment as it reacts with certain drugs, the lead residual after treatment is retained high in the blood enough to cause mental illnesses $6,7,8$.

Arsenic is recommended from the WHO guideline below $0.01 \mathrm{mg} / \mathrm{L}$ in drinking water. Data collected from three countries Australia, Canada, and the USA suggest people are exposed to $20 \mathrm{ug}$ of Arsenic per day from food and water and each country has its threshold for human arsenic exposure 9. Inorganic compounds can be used to treat leukaemia and psoriasis; organic compounds can be used in antibiotics for treating protozoal disease. However, arsenic can induce cancer when the high level of arsenic is present in water. Airborne arsenic can lead to lung cancer as scientists find a linear relationship between the disease and arsenic inhalation ${ }^{10}$. Although less poisoning than lead and used in treating cancer such as leukaemia, Arsenic has been on the decline of its use to reduce unexpected causes of poisoning.

Although case reports of heavy metal poisoning are rampant on scientific journals and newspapers, there is a lack of surveillance on domestic, commercial Ayurvedic drugs 11. Most surveys reveal heavy metals are also prevalent in Ayurvedic drugs in international markets. The amount of these metals is substantially high in a concentration above the regulated threshold. Daily intakes estimated from manufacturers' dosage of these metals surpasses 100 times of standard intakes 12. Many case reports from different countries' local markets record the issues of heavy metal contaminations over the intake limits 13, 14, 15, 16
Uses of heavy metals have become prevailing in manufactured Ayurvedic drugs. From a report of 230 random Ayurvedic drugs bought from the Internet in US and Indian markets, one-fifth of the drugs are reported containing lead, mercury, or arsenic. The effects of these metals remain unknown 17.

Several case reports show lead remained in the body after treatment causes adverse effects on patients. One recent case from Iowa Department Public Health, Iowa, USA reports $40 \%$ of 115 participants from a small town who had consumed Ayurvedic complementary medicines imported from India were tested had elevated blood lead level above 10ug/dl 18; at this blood lead level, a person can suffer from decreased cognitive performance and risk increasing blood pressure. Moreover, children and young adults are the most vulnerable to exposure to heavy metals as the potential of these heavy metals is out of control and children are more likely to receive the medicines from their parents without any consultation from doctors ${ }^{19}$.

\section{Herbal formulations.}

A factor contributing to the safety concern of Ayurvedic drugs is uncharacterized chemical constituents of Ayurvedic herbs. In principle, herbal drugs in Ayurvedic are not supposed to be extracted into individual components. Instead, these herbs would be kept comprising of multiple chemical constituents ${ }^{20}$. Chemical constituents can contribute synergetic effects on diseases; for example, reserpine, a chemical from Sarpagandha is only effective for treating hypertension if it is reserved with other constituents in the herb. However, certain chemical constituents in herbs can lead to side effects because not all chemical components are beneficial to treating diseases. For example, herbs in evening primrose oil are used for treating dermatitis contain y-linolenic acid which lowers the seizure threshold, making herb users more prone to seizure ${ }^{21}$.

Heavy metals can also contaminate herbs due to the metallic impurities released from industry or polluted areas ${ }^{22}$. It is worth determining the detailed concentration of each heavy metal if they are used in practices and assuring the complete removal of impurities ${ }^{23}$.

\section{Clinical research and approval of Ayurvedic drugs passed to markets.}

Drugs before approaching markets need to undergo several clinical trials. There are three main clinical phases tested on human models to guarantee the effectiveness and safety of tested drugs: after drugs have been proved safe and effective on animal models such as mice, phase 1 begins as drugs would be consumed by healthy volunteers to observe how 


\section{SJIF Impact Factor: 6.260| ISI I.F.Value:1.241| Journal DOI: 10.36713/epra2016 ISSN: 2455-7838(Online) \\ EPRA International Journal of Research and Development (IJRD) \\ Volume: 5 | Issue: 4 | April 2020 \\ - Peer Reviewed Journal}

drugs are metabolized and excreted. Phase 2 is initiated to test the effectiveness of drugs; either the target drugs or another drug such as a placebo would be consumed by a group of patients. Phase 3 would scale up the number of drugs to be tested on different populations of several hundred people; at this phase, the target drugs would vary in dosage for each group of people 24,25 .

The practice of Ayurvedic drugs has been deeply rooted since ancient times, and much Ayurvedic medicine has been widely used nowadays, especially among 80 per cent of the population in India. However, by advance in biomedicine and technology, the practice of herbal drugs could now be tested on its effectiveness and safety. Through more comprehensive screenings, several herbs are shown to unable to bring out helpful treatment as expected or even cause toxic effects on patients 26,27. To reduce cases of Ayurvedic drug poisoning, more clinical investigations are necessary to be conducted and drugs acceptable for treatments need to pass through critical trials as above.

Clinical investigations of Ayurvedic drugs in India are also limited. Data from Clinical Trials Registry - India (CTRI) suggest that from 2012 to 2016, out of 507 clinical investigations, 38 per cent of cases come from Gujarat, 19 per cent from Maharashtra, and 10 per cent from Karnataka. These statistical data show a lack of clinical registration or research from a majority of states ${ }^{28}$. Moreover, the majority of studies focuses on phase II (30.6 per cent) in which the studies were applied in small-scale population, while phase I consists of 9.9 per cent whereas 6.7 per cent in phase III ${ }^{28}$.

The cost of clinical trials creates obstacles for carrying out clinical investigations. Some study designs lack consistent sample sizes, especially in Phase II and Phase III 29. Licensing fees also contribute a burden to examining the quality of drugs.

\section{Manufacturing of Ayurvedic Drugs}

The government of India issued Drugs and Cosmetics Rules in 1945 and amendments in 2010 about the standard manufacturing procedures of drugs. A good manufacturing practice namely comprises of assured handling of raw material, manufacturing areas, quality control section, stores for distribution, and offices for doctors and data storage 30,31 .

In addition to the government's guidelines, manufacturers could resort to a purification process called Shodhana to detoxify certain poisonous herbs. Ayurveda claims there are some therapeutic values in poisonous herbs, and through the process of purification, poisoning chemical constituents in the herbs would be transformed into curative components. Purification mainly contains boiling certain herbs with a selected media, particularly cow's urine, cow's milk, coconut water. Cow urine, for example, is one of the most prominent media used in Ayurvedic detoxification. It is observable that the process removes, to some degree, of alkaloids such as strychnine and brucine which are leading to cardiotoxic and neurotoxic effects. However, the mechanism of purification and chemistry of cow's urine remains unclear ${ }^{32,33}$. Cow's urine is reported to be comprised of 95 per cent of water, 2.5 per cent of urea, and the rest, 2.5 per cent containing sodium, nitrogen, sulfur, and diluted ammonia. While Ayurveda puts much emphasis on certain hormones and minerals in cow's urine that play roles in removing poisons from herbs, more research on how these biochemical components can contribute to the purification process is still needed to clarify the reaction process. Even more, misunderstanding of cow's urine can lead to harm; the retained ammonia in cow's urine was reported to cause ocular surface injury in eyes ${ }^{34}$.

\section{DISCUSSION}

Lead, one of the common metals, added to Ayurvedic drugs for treatment purposes also becomes an issue. Lead, from Ayurvedic concepts, could be intentionally added to balance the health of people because the human's body is viewed incongruent with elements in the universe ${ }^{18}$. The imbalance of these metals in the human body is thought to cause diseases 19. However, it is not certain which sources the lead comes from and how added lead would benefit human health. There are many case reports of lead contamination due to the detoxification method, raising concerns over international regulations of using lead in medication.

Labelling information provided by drug markets is another alarming issue. A survey in Mumbai of drug labelling is set in 3 Ayurvedic pharmacies based on their availability of domestic, commercial drugs. Only 15 per cent out of 101 drugs are labelled with caution and warning of the ingredients and dosages ${ }^{35}$. Many of these drugs could be ordered by just over the counter without comprehensive prescriptions; hence, those consuming these drugs would potentially face risks of poisoning and overdose.

According to the Drugs and Cosmetics Act, 1940, the expiry date of drugs is not generally required for domestic drugs. Many products are found unlabeled of the expiry date. This causes a problem because some herbs are only effective for months ${ }^{35}$.

Regarding the materials within the herbal products, there are quite a few numbers of companies facing issues of adulteration of raw materials, making the ingredients unfit for the labelling information ${ }^{36}$. 


\section{SJIF Impact Factor: 6.260| ISI I.F.Value:1.241| Journal DOI: 10.36713/epra2016 ISSN: 2455-7838(Online) \\ EPRA International Journal of Research and Development (IJRD) \\ Volume: 5 | Issue: 4 | April 2020 \\ - Peer Reviewed Journal}

The International Ayurvedic drug market also is faced with some loopholes. The prevalence of nonprescription medicines is relatively high among international Asian markets such as one in Phoenix, Arizona of the US. These drugs do not include clear instructions and dosage per usage, or some are labelled with inadequate information such as no list of ingredients and non-English languages 37,38 . When examined, the concentration of heavy metals surpasses toxicity levels.

\section{CONCLUSION}

Suggestions on improving the quality of Ayurvedic drugs.

Clinical research of Ayurvedic drugs plays a vital role in determining the safety of commercial drugs. Most of the Ayurvedic research focuses are conducted in vitro. Research on human models is deprived and needed more to provide concrete evidence for treating certain disease ${ }^{39}$.

Research and validation of Ayurvedic drugs also involve many external issues. One of the main questions revolves around the means of investigation in Ayurvedic drugs. Should research on Ayurvedic drugs be as same as research on biomedical drugs? As such, there is not any clear consensus on the research method ${ }^{40}$. However, to confirm standard, global safety in drug commercialization, Ayurvedic drugs need to undergo biomedical testing and several clinical trials. Still, biomedical testing is also faced with its control methods which commonly deal with few chemical compounds, while herbal medicines contain a bundle of chemicals inside.

Furthermore, should there be any change in ideological perspective in practising Ayurvedic medicines? Ayurvedic practices have intertwined with religion for a thousand years ${ }^{41}$. Although this relationship brought up many beneficial values in the overview of human health, certain underlying believes, nonetheless, are no longer practical under the scope of modern medicine. As have been shown, heavy metals in medicines could not prove its effectiveness in medical treatment. Even the intake of these compounds can cause reverse effects on health. It is essential to the Ayurvedic practice that needs to be altered so the practice could adapt to the new era of human medicine. If using heavy metals is causing more harm than good, why do we not look for a better practice that gets rid of unnecessary heavy metals? To change certain methods in practising Ayurvedic medicines does not mean to eliminate the root of Ayurveda. Instead, doing so would navigate the practice towards the better treatment for human health, making the drugs more of potential medicines and commercialized in the world.

For the Ayurvedic drugs become more effective, research, especially clinical investigations should be more centred at the molecular chemistry of constituents within Ayurvedic medicines such as herbs. As we stated above, not every chemical compound in herbs could possess therapeutic potentials to treat diseases; some constituents are even inimical to the health patients. Thus, the process of purification has to be assured of eliminating all or at most unbeneficial chemicals within the medicines.

Clinical investigations are vital to control the safety and potency of drugs. Many drugs have been used in the past but now are reported causing harm to its users. Clinical research is so critical to ascertaining the quality of drugs. Even more, clinical trials were reported showing inconsistency in the number of research subjects. Especially, phase III of clinical investigation has to be implemented extensively in large-scale, different populations before the drugs are passed to markets.

\section{Acknowledgement}

Am very grateful to my study abroad students ( Most of them from the US) to express their ideology about our traditional system of Ayurveda, without any hesitation with facts and figure. It shows we Indian ayurvedic scholars have to do more work to vanish their opinion. and show the right path to them.

\section{REFERENCES}

1. Patwardhan, B. (2012). The quest for evidencebased Ayurveda: Lessons learned. Current Science, 102(10), 1406-1417. Retrieved from http://www.jstor.org/stable/24107798

2. Douros, A., Bronder, E., Andersohn, F., Klimpel, A., Kreutz, R., Garbe, E., \& Bolbrinker, J. (2016). Herb-Induced Liver Injury in the Berlin CaseControl Surveillance Study. International journal of molecular sciences, 17(1), 114. doi:10.3390/ijms17010114

3. Singh, R., Gautam, N., Mishra, A., \& Gupta, R. (2011). Heavy metals and living systems: An overview. Indian journal of pharmacology, 43(3), 246-53.

4. Dagma W. (2013). Perfect Medicine: Mercury in Sanskrit Medical Literature. Asian Medicine. Tradition and Modernity, 8(1):1-26.

5. J.F. Risher (2003). Elemental Mercury And Inorganic Mercury Compounds: Human Health Aspects. Concise International Chemical Assessment Document 50. WHO

6. Helen G. (2002). Lead, unsafe at any level. Bulletin of the World Health Organization. 80 (1). $\mathrm{WHO}$

7. Reyes, J.W. (2018). A Social Justice Framework for Lead Policy. JAMA pediatrics, 172 10, 912914.

8. WHO Training Package for the Health Sector (2011). Adverse Health Effects Of Heavy Metals In Children. WHO

9. IARC Working Group on the Evaluation of Carcinogenic Risk to Humans. Arsenic, Metals, 


\section{EPRA International Journal of Research and Development (IJRD)}

Fibres and Dusts. Lyon (FR): International Agency for Research on Cancer; 2012. (IARC Monographs on the Evaluation of Carcinogenic Risks to Humans, No. 100C.) ARSENIC AND ARSENIC COMPOUNDS. Available from: https://www.ncbi.nlm.nih.gov/books/NBK304380/

1. 11 Thatte, U., \& Bhalerao, S. (2008). Pharmacovigilance of ayurvedic medicines in India. Indian journal of pharmacology, 40(Suppl 1), S10-2.

2. 12 Saper R. B., Kales S.N., Paquin J., et al. Heavy Metal Content of Ayurvedic Herbal Medicine Products. JAMA. 2004;292(23):28682873. doi:10.1001/jama.292.23.2868

3. 13 Mathee, A., Naicker, N., \& Teare, J. (2015). Retrospective Investigation of a Lead Poisoning Outbreak from the Consumption of an Ayurvedic Medicine: Durban, South Africa. International journal of environmental research and public health, 12(7), doi:10.3390/ijerph120707804

4. 14 Hajra B., Qayum I., Orakzai S., Hussain F., Faryal U., Aurangzeb. (2015). Evaluation Of Toxic Heavy Metals In Ayurvedic Syrups Sold In Local Markets Of Hazara, Pakistan. J Ayub Med Coll Abbottabad. 27(1):183-6.

5. 15 Saper RB, Kales SN, Paquin J, et al. Heavy Metal Content of Ayurvedic Herbal Medicine Products. JAMA. 2004;292(23):2868-2873. doi:10.1001/jama.292.23.2868

6. 16 J Araujo, AP Beelen, LD Lewis, GG Robinson, $C$ DeLaurier, $M$ Carbajal, B Ericsson, $Y$ Chin, $K$ Hipkins, SN Kales, RB Saper, $R$ Nordness, $R$ Rabin, $N$ Jeffery, J Cone, C Ramaswamy, $P$ Curry-Johnson, KH Gelberg, J Paquin, DM Homa, and RJ Roscoe.(2004). Lead poisoning associated with ayurvedic medications--five states, 2000-2003. MMWR. Morbidity and mortality weekly report, 53(26), 582-4.

7. 17 Saper, R. B., Phillips, R. S., Sehgal, A., Khouri, N., Davis, R. B., Paquin, J., Thuppil, V., ... Kales, S. N. (2008). Lead, mercury, and arsenic in USand Indian-manufactured Ayurvedic medicines sold via the Internet. JAMA, 300(8), 915-23.

8. 18 Breeher, L., Mikulski, M. A., Czeczok, T., Leinenkugel, K., \& Fuortes, L. J. (2015). A cluster of lead poisoning among consumers of Ayurvedic medicine. International Journal of occupational and environmental health, 21(4), 303-7.

9. 19 E. Ernst. (2002). Heavy metals in traditional Indian remedies. Eur J Clin Pharmacol. 57(12): 891-896.

10. 20 Nandini K. K., Pradeep K. D. (2016). Status of regulation on traditional medicine formulations and natural products: Whither is India? Current science. 111(2):25-2016. DOI: 10.18520/cs/v111/i2/293-301

11. 21 Shenefelt P.D. Herbal Treatment for Dermatologic Disorders (2011). Benzie IFF, Wachtel-Galor S, editors. Herbal Medicine: Biomolecular and Clinical Aspects. 2nd edition. Boca Raton (FL): CRC Press/Taylor \& Francis.
Chapter $18 . \quad$ Available from: https://www.ncbi.nlm.nih.gov/books/NBK92761/

12. 22 Vartika R., Poonam K., Sayyada K., A.K.S. Rawat \& Shanta M. (2001) Heavy Metal Accumulation in Some Herbal Drugs, Pharmaceutical Biology, 39:5, 384-387, DOI: 10.1076/phbi.39.5.384.5898

13. 23 Clinio L., Dora M. and Marcello L. (2014). "Toxic Metals in Herbal Medicines. A Review", Current Bioactive Compounds. 10: 181. https://doi.org/10.2174/157340721066614071616 4321

14. 24 WHO. (1995). Guidelines for good clinical practice (GCP) for trials on pharmaceutical products. WHO Technical Report Series, No. 850, 1995, Annex 3

15. 25 US Food \& Drug Administration (2017). The FDA's Drug Review Process: Ensuring Drugs Are Safe and Effective. Retrieved from https://www.fda.gov/Drugs/ResourcesForYou/Co nsumers/ucm143534.htm

16. 26 Nasrin, S., Bachar, S. C., \& Choudhuri, M. S. (2011). Toxicological studies of "Chondrokola Rosh", an Ayurvedic preparation on liver function tests of rats. African journal of traditional, complementary, and alternative medicines : AJTCAM, 8(5 Suppl), 170-4.

17. 27 Kulkarni, S K, Kiran K. A., Ashish D. (2008). Effect of Withania somnifera Dunal root extract against pentylenetetrazol seizure threshold in mice: Possible involvement of GABAergic system. 465-469. Retrieved from http://hdl.handle.net/123456789/4502

18. 28 Bolshete P. M., (2017). Analysis of ayurvedic clinical trials registered in clinical trials registry of india: retrospective versus prospective registration. Ancient Science of Life. 37(1):9-15.

19. 29 Safiaghdam, H., Oveissi, V., Bahramsoltani, R., Farzaei, M., Rahimi, R. (2018). Medicinal plants for gingivitis: a review of clinical trials. Iranian Journal of Basic Medical Sciences, 21(10), 978991. doi: 10.22038/ijbms.2018.31997.7690

20. 30 Government of India, Ministry of Health and Family Welfare. The Drugs And Cosmetics Act, 1940 \& Drugs And Cosmetics Rules, 1945. Amended 2016.

21. 31 Kishor P., Jigyasa P., Rabinarayan A. (2017). Ayurveda formulations: A roadmap to address the safety concerns. Journal of Ayurveda and Integrative Medicine. Volume 8, Issue 4, Pg. 279282, ISSN 0975-9476, https://doi.org/10.1016/j.jaim.2017.08.010.

22. 32 Mitra, S., Shukla, V. J., \& Acharya, R. (2011). Effect of purificatory measures through cow's urine and milk on strychnine and brucine content of Kupeelu (Strychnos nuxvomica Linn.) seeds. African journal of traditional, complementary, and alternative medicines : AJTCAM, 9(1), 105-11.

23. 33 Ilanchezhian R., Roshy Joseph C., Rabinarayan A. (2010), Importance of Media in Shodhana (Purification / Processing) of 
Poisonous Herbal Drugs. Ancient Science of Life, Vol. 30, No.2. Pg. 54 - 57

24. 34 Khanduja, S., Jain, P., Sachdeva, S., \& Phogat, J. (2017). Cow Urine Keratopathy: A Case Report. Journal of clinical and diagnostic research : JCDR, 11(4), ND03-ND04.

25. 35 Bhalerao, S., Munshi, R., Tilve, P., \& Kumbhar, D. (2010). A survey of the labeling information provided for ayurvedic drugs marketed in India. International journal of Ayurveda research, 1(4), 220-2.

26. 36 Sahoo, N., \& Manchikanti, P. (2013). Herbal drug regulation and commercialization: an Indian industry perspective. Journal of alternative and complementary medicine (New York, N.Y.), 19(12), 957-63.

27. 37 Levine, M., Mihalic, J., Ruha, A. M., French, $R$ N., \& Brooks, D. E. (2012). Heavy metal contaminants in yerberia shop products. Journal of medical toxicology : official journal of the American College of Medical Toxicology, 9(1), 21-4.

28. 38 I. Dargan, Paul \& B. Gawarammana, Indika \& R.H. Archer, John \& M. House, Ivan \& Shaw, Debbie \& M. Wood, David. (2008). Heavy metal poisoning from Ayurvedic traditional medicines: An emerging problem?. Int. J. Environment and Health. 2. 10.1504/IJENVH.2008.020936.

29. 39 Shenefelt P.D. (2011). Herbal Treatment for Dermatologic Disorders. In: Benzie IFF, Wachtel-Galor S, editors. Herbal Medicine: Biomolecular and Clinical Aspects. 2nd edition. Boca Raton (FL): CRC Press/Taylor \& Francis. Chapter $18 . \quad$ Available from: https://www.ncbi.nlm.nih.gov/books/NBK92761/

30. 40 Laurent P. (2014). Pervious Drugs: Making the Pharmaceutical Object in Techno-Ayurveda. Asian Medicine. Volume 9, Issue 1-2, pg. 49-76. DOI: 10.1163/15734218-12341292

31. 41 Sita R. (2002). Asian Medicine in America: The Ayurvedic Case. The ANNALS of the American Academy of Political and Social Science.

https://doi.org/10.1177/000271620258300107 